\title{
LONG-TIME AGING BEHAVIOUR OF THE ALLOY Al-2024 CHARACTERIZED BY POSITRON ANNIHILATION SPECTROSCOPY
}

\author{
E.-M. Nicht, G. Brauer \\ Research Centre Rossendorf Inc., P.O. Box 510119, 01314 Dresden, Germany \\ AND G. TEMPUS \\ EADS Airbus GmbH, Hünefeldstraße 1-5, 28199 Bremen, Germany
}

\begin{abstract}
The reconstruction of the precipitation structure after solution treatment has been investigated by positron annihilation spectroscopy. In this study the behaviour of samples taken from an aircraft "Airbus 300 ", being in operation for 18 years, is compared to a reference material supplied by Alcoa. The results of position annihilation spectroscopy show that there are no significant differences in both materials. This finding is in agreement with the results obtained from other methods within the scope of the general research program which points to a materials behaviour as predicted for a safe operation of this type of aircraft.
\end{abstract}

PACS numbers: $78.70 . \mathrm{Bj}$

\section{Introduction}

These investigations are part of a larger program established by Airbus Industries to characterize the aging behaviour of the alloy Al-2024 used in the fabrication of the aircraft "Airbus". The chemical composition of this alloy is given in Table.

Positron annihilation spectroscopy (PAS) is a method which is sensitive to defects in a microscopic and atomic scale. Positrons may be trapped by vacancies, voids, dislocations, semicoherent and incoherent particles, and coherent precipitates such as Guinier-Preston zones (GPZ). Therefore during the last years the positron method has turned out to be a potential tool for studying decomposition phenomena in alloys, especially in $\mathrm{Al}[1-3]$.

The formation of the GPZ already occurs at (or near to) room temperature. During aging metastable phases are formed and then disappear or are transformed into more stable precipitates which are fully incoherent to the matrix. The sequence 
TABLE

Chemical composition of Al-2024.

\begin{tabular}{c|c|c|c|c|c|c|c|c|c}
\hline \hline \multicolumn{2}{c|}{$\mathrm{Cu}$} & \multicolumn{2}{c|}{$\mathrm{Mg}$} & \multicolumn{2}{c|}{$\mathrm{Mn}$} & \multicolumn{2}{c|}{$\mathrm{Si}$} & \multicolumn{2}{c}{$\mathrm{Fe}$} \\
\hline wt\% & at\% & wt\% & at\% & wt\% & at\% & wt\% & at\% & wt\% & at\% \\
\hline 4.4 & 1.92 & 1.5 & 1.66 & 0.7 & 0.345 & 0.5 & 0.48 & 0.5 & 0.24
\end{tabular}

of stages in the decomposition process depends on the composition of the alloy, the quenching conditions, the aging temperature and the time [4].

In this work the positron data for the $85^{\circ} \mathrm{C}$ aging after solution treatment of a reference material supplied by Alcoa (named FT) and samples taken from an aircraft "Airbus 300 ", being in operation for 18 years (named T), are presented and discussed.

\section{Experimental}

The samples for the PAS were prepared by cutting of $8 \times 8 \mathrm{~mm}$ pieces from the corresponding sheet. The sample-source-sample-sandwich was fixed in a position that positron lifetime and $S$ parameter were measured at the same time. The parameters of the device are published elsewhere [5]. To study the reconstruction of the precipitation structure after the solution treatment $\left(495^{\circ} \mathrm{C} / 20 \mathrm{~min} /\right.$ quenching in water) the samples were aged at $85^{\circ} \mathrm{C}$ and the positron annihilation data were measured at room temperature in the following sequence:

0/1/2/4/8/16/32/64/128/256/512/1000 h.

For the fitting of the time spectra an updated version of the well-known POSITRONFIT EXTENDED program package [6] was used.

The line-shape parameter $S$ is a measure of annihilations of positrons with conduction or valence electrons. For the calculation a small portion in the centre of the measured Doppler-broadened $511 \mathrm{keV}$ spectrum is divided by the total area of the spectrum.

The wing parameter $W$ is the sum of two segments on either side of the peak and therefore associated with core electrons alone. The relative $S$ parameter $S_{\text {rel }}$ is calculated by

$$
S_{\text {rel }}=S_{n} / S_{\text {ref }}
$$

with $S_{n}$ as value for the current measurement and $S_{\text {ref }}$ for the $S$ parameter of a reference material of well annealed defect-free pure Al.

\section{Results and discussion}

In Fig. 1 the results of positron lifetime (a) and $S$ parameter measurements (b) for the $85^{\circ} \mathrm{C}$ aging after solution treatment are presented. The positron annihilation data reflect the reconstruction of the precipitation structure after the solution treatment during the $85^{\circ} \mathrm{C}$ aging. The interpretation of PAS results in 

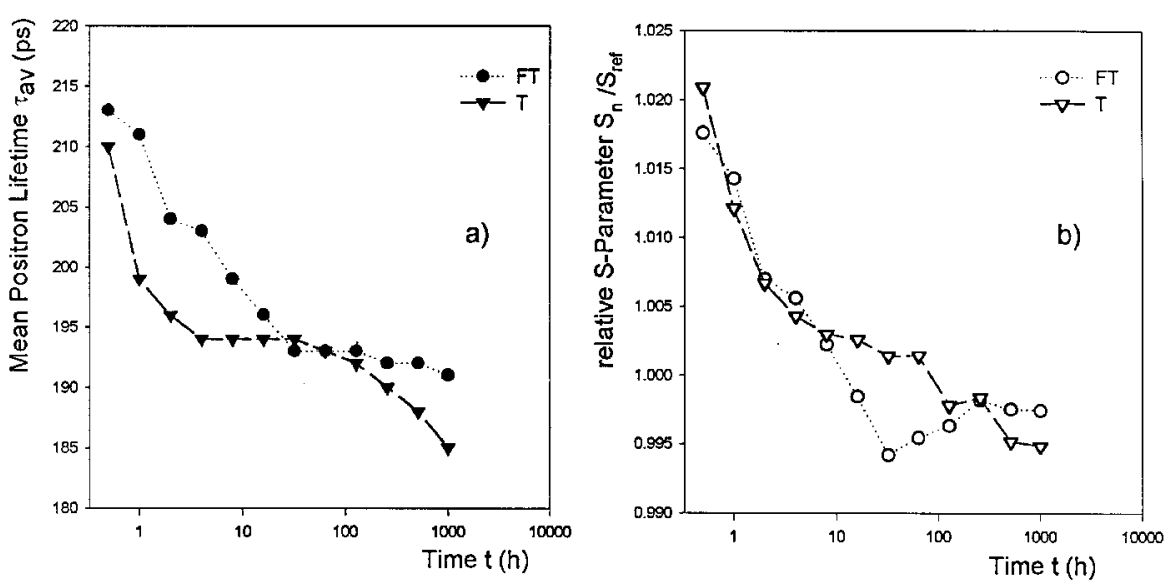

Fig. 1. Mean positron lifetime (a) and $S$ parameter (b) for the $85^{\circ} \mathrm{C}$ aging after solution treatment of a reference material (FT) and a sample taken from an aircraft (T).

terms of the reconstruction of the precipitation structure after solution treatment needs, however, support from previous knowledge, for example from various microscopies or small-angle X-ray scattering (SAXS).

From the results of such investigations it is known that precipitation in Al-2024 after solution treatment occurs via a series of metastable Al-Cu phases [7].

The formation and growth of such precipitates results in the decrease in the mean positron lifetime and $S$ parameter (Fig. 1a, b) for both materials during the $85^{\circ} \mathrm{C}$ aging after the solution treatment. To get information whether only one or several types of defects are responsible for the positron trapping, for both materials the $W$ parameter was calculated and used in the $S(W)$ plot (Fig. 2a,b).

Based on the trapping model, the analysis of the $511 \mathrm{keV}$ radiation line shape leads to a defect-specific parameter $R$ [8-10]. Changes of a parameter $S(W)$ in a series of measurements can be caused either by the type or by the concentration of the defect. The characteristic $R$ parameter is defined by

$$
R=\left(S_{i}-S_{1}\right) /\left(W_{i}-W_{1}\right),
$$

with $S_{1}, W_{1}$ for the reference measurement and $S_{i}, W_{i}$ for the current measurements in the series. $R$ is concentration independent and characterizes the type of trapping site involved. This is valid if only one type of trapping centre is present. Drawing a $S(W)$ plot the points form in this case a straight line with the slope $R$.

The corresponding $S(W)$ plots calculated from the data of the line-shape measurements are given in Fig. 2a and b.

From these graphs for both materials three steps in the $85^{\circ} \mathrm{C}$ aging after solution treatment up to an aging time of $1000 \mathrm{~h}$ can be clearly distinguished

1. $0-2 \mathrm{~h}$,

2. $2-16 \mathrm{~h}$,

3. $32-1000 \mathrm{~h}$.

According to the literature the first step reflects mainly annihilations in vacancies frozen by the quenching process $[1,3,4]$. 

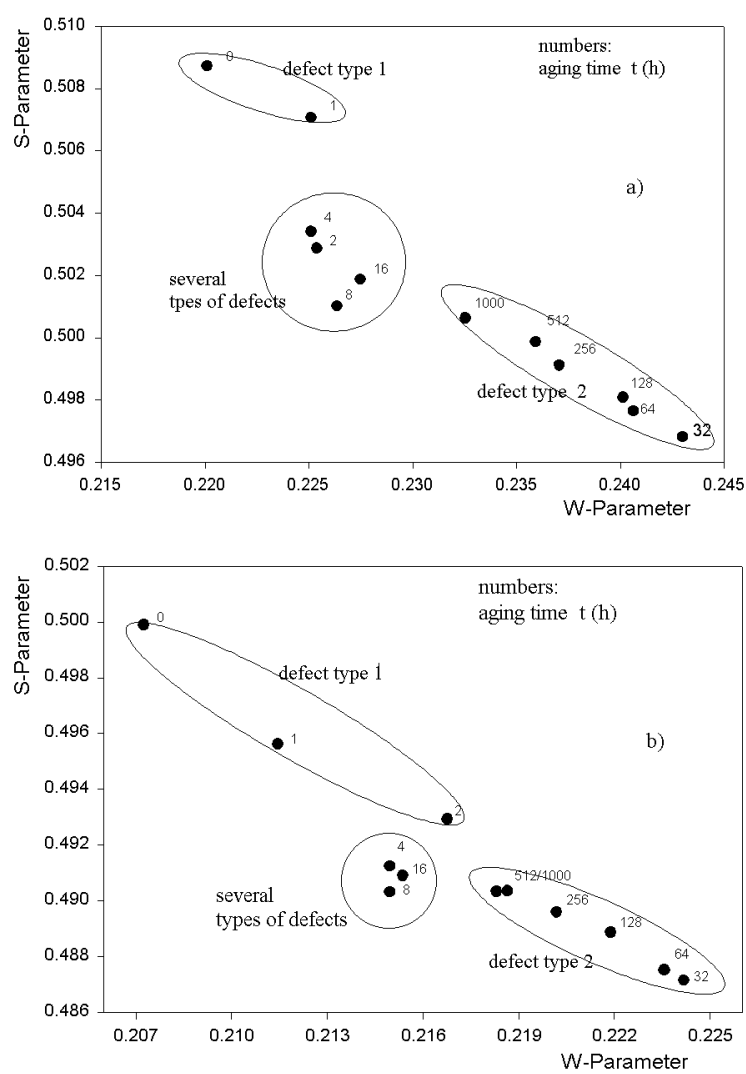

Fig. 2. $S(W)$ plot for the $85^{\circ} \mathrm{C}$ aging after solution treatment of a reference material (a) and a sample taken from an aircraft (b).

In the second step the graph forms a cloud of points and not a straight line. In this case according to the trapping model the positron trapping is caused by several types of defects. For aging times $>16 \mathrm{~h}$ the measured data result in the $S(W)$ plot in a nearly straight line. This indicates on the one hand that only one type of defect is present, and on the other hand that changes in the positron data must be caused by changes in the defect concentration. From the results of additional SAXS-measurements and discussions in the literature [7] it can be concluded that the mentioned defects are $\mathrm{Al}-\mathrm{Cu}$ precipitates. Because the positron affinity $A_{+}[11]$ of $\mathrm{Cu}(-4.81 \mathrm{eV})$ is higher than that of $\mathrm{Al}(-4.41 \mathrm{eV})$, positrons are trapped in these precipitates if they reach a critical radius $r_{c}$ during the aging time.

The results of the positron lifetime and $S$ parameter measurements as well reflect an increase in the concentration of $\mathrm{Al}-\mathrm{Cu}$ precipitates for aging times between 16 and $1000 \mathrm{~h}$ and show no significant differences between both materials.

The presented results of PAS indicate in addition that the reconstruction of the precipitation structure after solution treatment is not finished after an aging time of $1000 \mathrm{~h}$ at $85^{\circ} \mathrm{C}$. 


\section{Conclusions}

The reconstruction of the precipitation structure after solution treatment has been investigated by PAS. In this work the behaviour of samples taken from an aircraft "Airbus 300 ", being in operation for 18 years $(\mathrm{T})$, is compared to a reference material supplied by Alcoa.

The results of PAS presented in this work prove that there are no differences in the aging behaviour after solution treatment of both materials.

\section{References}

[1] G. Dlubek, Mater. Sci. Forum 13/14, 11 (1997).

[2] R. Braun, C. Juricic, G. Tempus, unpublished results, DaimlerChrysler Airbus Aerospace GmbH.

[3] A. Dupasquier, P. Folegati, N. de Diego, A. Somoza, J. Phys., Condens. Matter 10, 10409 (1998).

[4] R. Ferragut, A. Somoza, A. Dupasquier, J. Phys., Condens. Matter 10, 3903 (1998).

[5] E.-M. Nicht, G. Brauer, P. Vostry, M. Cieslar, P. Blazek, Nukleonika 10, 175 (1997).

[6] P. Kirkegaard, N.J. Pedersen, M. Eldrup, Tech. Rep. Risø Nat. Lab., Roskilde (Denmark) 1989.

[7] W.B. Gauster, W.R. Wampler, Philos. Mag. A 41, 145 (1980).

[8] W. Triftshäuser, Phys. Rev. B 12, 4634 (1975).

[9] S. Mantl, W. Triftshäuser, Phys. Rev. B 17, 1645 (1978).

[10] G. Brauer, Werkstoffanalytische Verfahren, Ed. H.-J. Hunger, Deutscher Verlag für Grund-stoffindustrie, Leipzig 1995, p. 524.

[11] M.J. Puska, P. Lanki, R.M. Nieminen, J. Phys., Condens. Matter 1, 6081 (1989). 